\title{
Introducción al estudio del sindicalismo confesional valenciano *
}

\author{
José Manuel Cuenca Toribio
}

\begin{abstract}
RESUMEN ABSTRACT

Evolución de la acción social cristiana Evolution of the social action christens en una de las regiones con mayor impetu asociativo del primer tercio del siglo xx. La movilización política y social de una poderosa población cristiana fue el dato mayor, probablemente, de la dinámica política y social del País Valenciano, con aspectos tan curiosos y desconocidos como el sobresaliente protagonismo femenino en los ámbitos de la convivencia asociativa. in one of the regions with major associative impetus of the first third of the century $x x$. The political and social mobilization of a powerful Christian population was the major information, probably, of the political and social dynamics of the Valencian Country, with aspects so curious and unknown as the excellent feminine importance in the areas of the associative living together.

PALABRAS CLAVE

Catolicismo social, asociacionismo KEY WORDS

Social Catholicism, social associative, social, País Valenciano, siglo Xx. Valencian Country, century $x x$.
\end{abstract}

Obligada y principal escala en la reconstrucción del catolicismo social español, el País Valenciano emerge como una de sus cotas más descollantes. De ahí, por ende, que las referencias a sus hombres - y mujeres,

* Estas páginas se destinaron en su versión primitiva al libro de homenaje del Prof. D. Ángel Martínez de Velasco. Al no tener, por su temática, cabida específica en la mencionada obra se acogen ahora al patrocinio de la prestigiosa revista Espacio, Tiempo y Forma, peraltando, si ello fuera posible, la nota de alta estima intelectual y humana por el entrañable amigo desaparecido. 
muchas en tiempos en que eran impensables cuotas y porcentajes femeninos... - y episodios sean recurrentes en cualquier análisis del tema, incluso en uno modesto y apresurado como el presente. Al igual que sucediera con el castellano-leonés o el navarro-riojano, sobre sus vigas maestras descansó el edificio del sindicalismo confesional hispano. Los estudios que recientemente ha motivado sirven para comprobar, no obstante la habitual tendenciosidad de sus enfoques, la trascendencia del socialcatolicismo levantino, muchas veces relegada por el castellanocentrismo imperante en la, por lo demás, raquítica bibliografía del movimiento a escala nacional. Pese al cicatero arnés y al hipercriticismo de los investigadores más imparciales entre los de unas generaciones de contemporaneístas caracterizados por el apriorismo de sus posiciones, la importancia de la experiencia sindical católica valenciana - dentro de las cuadrículas temporales y económico-sociales de la España del periodo- resalta en cada tramo de su estudio. En Segorbe, La Plana o La Safor -comarca o Huerta de Gandía, más precisamente- sus realizaciones se impusieron a cacicatos, escepticismos y trastabilleos, a los que, ciertamente, ninguna clase o estrato dejó de contribuir. El limpio esfuerzo, la pulsión animosa y la hondura de las convicciones de los mejores de sus miembros se sobrepusieron a ruindades y desaciertos para elevar la condición económica, cultural y moral de una parte considerable de los afiliados a círculos y sindicatos. Crédito financiero, tecnología, libros y periódicos, representaciones teatrales y algún que otro sermón de escucha no siempre obligatoria contribuyeron a ello, con una movilización de energías y voluntades nunca baladí, pues potenció, en tierra no muy abonada, cierto sentido comunitario y una sociabilidad nada despreciable.

Suelo nutricio y tierra solariega del catolicismo social español, la realidad finisecular valenciana materializó gran parte de los sueños iniciales de su impulsor y pionero. Según sus cuentas - Socialismo y anarquismo..., 1893 - por estas fechas cerca de medio centenar de círculos y patronatos testimoniaban en la geografía del viejo reino de Valencia - 0 , más correctamente, del arzobispado valentino y del territorio castellonense perteneciente a la sede deurtosense - lo fecundo del esfuerzo inicial. $Y$ un año desp és que en ésta, en 1896 se creaba en la ciudad del Turia el "Gremi de L:auradors», prueba de la capacidad autocrítica de Vicent y del permanente proceso de renovación de su proyecto, casi siempre contra viento y marea ${ }^{1}$. Al contrario que en otras zonas del país, en ésta todo co-

\footnotetext{
El mismo Vicent, que en junio de 1894 definia a Sancha como el prelado «más ladino y avanzado que tenemos en España», le atribuiría un año y medio más tarde la inspiración directa
} 
menzó con orden, y sería el «Círculo Católico Obrero de San Vicente Ferrer», emplazado en la capital levantina, el primero en implantarse -finales de junio de 1881-. Tres años después, también en otra primavera, alcanzaría existencia legal en la misma capital el «Patronato de la Juventud Obrera», obra de sorprendente eficacia, una de las cuatro instituciones mencionadas nominatim como modélicas de acción social cristiana en las conclusiones del III Congreso Católico, celebrado en Sevilla en 1882, a socaire del IV Centenario del descubrimiento de América. Un poco antes, y en Liria, había comenzado un reguero interminable, que en 1891 animaba la vida social y económica de casi una veintena de localidades valencianas: Ollería, Masamagrell, Torrente, Játiva, Manises, Burjasot, Alzira, Onteniente, Sueca, Paterna, Carcagente, Algemesí, Chiva, Godella...; dobladas un decenio más tarde para hacer de la sede el vértice cuantitativo y, en buena medida, cualitativo de los Círculos católicos españoles. Lastrados con múltiples rémoras, aquejados de encorsetamientos y disfuncionalidades, incluso deturpados en algunas ocasiones, tales centros dieron cobijo en su fugaz o dilatada andadura a nobles ideales y realizaciones de innegable valía. Descalificar o amenguar su valor por su incardinación en comarcas propicias a su despliegue, como las litorales y en todas en las que predominaba la pequeña y mediana propiedad o mayor era el envite de organizaciones obreras de signo opuesto, descubre un errado prejuicio, al no comprender cómo los círculos y sindicatos de la región respondían a una demanda en la que se mezclaban razones de toda factura, alguna de ellas, como las religiosas, indeficientemente orilladas en su estudio. La decisiva intervención que tuvieran a comienzos de siglo en la erección de la leprosería de Fontilles el P. Ferris, Joaquín Ballester o Vicente Sáenz de Juano Rignon, todos ellos conspicuos protagonistas de la primera andadura del sindicalismo gandiese ilustra insuperablemente tal faceta del movimiento católico aludido, entre otros numerosos ejemplos sobre los que cae una granítica losa de silencio, también, siguiendo el discurso historiográficamente corrrecto, en estas páginas... ${ }^{2}$.

\footnotetext{
de la conversión de los círculos en gremios y cofradías. Cf. R. M. SANz DE DiEGo, «El catolicismo social español ante la peregrinación obrera de 1894», Estudios Eclesiásticos, 55 (1980), págs. 19 y 25 y A. GonzÁlez SOBACO, Los partidos políticos durante la Segunda República en Castellón. Castellón, 1986, pág. 24. Un buen encuadramiento en V. CARCEL. ORTI, Historia de la lglesia en Valencia. Valencia, 1997, II, págs. 672 y ss.

2 «Paral-lelament, la familia s'implicava també en la magna obra benèfica del moviment catòlic: Fontilles. Vicente Sáenz de Juano García recordava perfectament la gran influència que el pare Carles Ferrís va tenir entre els senyors i les senyores de Gandia". J. E. Alonso, Saénz de Juano. Valldigna, 2002, pág. 30. Acerca de J. Ballester escribe con emoción rara en un escritor de pluma buida y documentada: «He escrito biografías de hombres grandes y universales, como
} 
Con un manantial que todavía no daba señal ninguna de agotamiento, se corría el peligro de la dispersión. En el arranque del siglo -1902surgía en una Valencia sacudida por la tensión política la «Unión Social Cristiana", un paso adelante, organizativa y doctrinalmente, en el camino hacia la sindicación y unidad efectiva de los trabajadores. De ella saldría, en línea directa, la institución requerida por los nuevos tiempos. En 1908, el "Círculo de San Vicente Ferrer» se refundía en la "Casa de los Obreros de San Vicente Ferrer», «Federación de Sindicatos Profesionales de Obreros Industriales». Por sus pasos contados, el cambio que transformaba los círculos en sindicatos se había llevado a cabo en una Valencia que recibiera el año anterior el merecido reconocimiento por la intelligentzia socialcatólica, al celebrarse en ella la segunda de las "Semanas Sociales", convención anual durante el sexenio ulterior de los estados mayores del movimiento. Apenas un mes antes de que Vicent muriese en el famoso colegio de San José, la obra del catolicismo social de la ciudad levantina parecía cerrarse con la apertura de un "Sindicato de la Aguja», destinado a erigirse como centro modélico de los muchos de igual textura esparcidos por todo el país y núcleo irradiador de otras pujantes iniciativas en el marco del asociacionismo obrero femenino de la región ${ }^{3}$.

Por supuesto, el campo tampoco dejó de expresar la vitalidad del socialcatolicismo levantino. Escenario predilecto de la restauración jesuítica operada durante el canovismo, los centros educativos de Orihuela o Gandía -éste último también formativo de los propios cuadros ignacianosconcurrieron a la tarea impulsada por Vicent, que tuvo la fortuna de encontrar en el P. Carlos Ferris (1856-1924), alma del centro gandiense, un discípulo de envidiable talla. En el bienio 1893-5 surgirán, al socaire, en ancha medida, de sus esfuerzos, los círculos de Gandía y Benirredrá. De vida no muy próspera recibirán a comienzos de siglo el refuerzo de otras

\footnotetext{
Pedro Arrupe y Juan Pablo Il; de santos fundadores y figuras sorprendentes como Ignacio de Loyola y Pedro Claver; de curas y monjas más anónimos [...] Pero nunca hubiera creído que un cristiano que llegó a ser alcalde y candidato a diputado en Cortes, y que de joven era un rico hacendado, reuniera en sí facetas tan dispares como las de político, voz de los sin voz, defensor de los obreros, activista social, agricultor, propietario, cristiano, economista, mendicante voluntario, benefactor incansable, luchador contra la usura, favorecedor del ahorro, fundador de la primera leprosería en España, entre otras muchas cosas más, y sobre todo apóstol de Jesucristo hasta llegar a morir sin un duro, pobre entre los poibres, y ser proclamado "santo" antes de su fallecimiento por una ciudad entera que quiso asistir masivamente a su viático". P. M. LAMET, Un hombre para los demás. Joaquín Ballester Lloret, fundador de Fontilles (1865-1951). Santander, 2001, pág. 13.

3 Vid. el libro sin pretensiones pero muy útil y perspicaz en muchos pasajes de C. Ruiz RoDRIGo, Catolicismo social y educación. La formación del proletariado en Valencia (1891-1917). Valencia, 1982.
} 
sociedades de igual identidad en Xeraco -1901-, Oliva -1904, "Gremio de Labradores de S. Antonio Abad", que en 1910 daría paso a un "Círculo Católico»-, e, incluso en la misma patria de San Francisco de Borja, el de la "Unión Católica Gandiense» -1904-. La superación de las lentitudes y trastabilleos iniciales fue espectacular en esta comarca al crearse en 1908 la «Federación Católica de Sindicatos Agrícolas» del distrito de Gandía, algunos de cuyos centros radicaban más allá de las fronteras de La Safor, como los de Ondara o Pedreguer, en la Marina Alta ${ }^{4}$. Un poco más tarde, en la primera recepción del movimiento sindicalista cristiano, nacería en Alcudia de Carlet y con el mismo origen -círculo católico fundado en 1892, pronto deprimido después de una arrancada vigorosa- el sindicato "La Protectora» - julio, 1912-. Su principal singularidad descansaría quizás en el hecho de ser el segundo de los asentados en la pequeña localidad cercana a Valencia y, por ende, influida por el intenso movimiento político-ideológico de la capital levantina de principios del $x x$. En efecto, fue un médico - y gran propietario por vía conyugal-, el Dr. Manuel Goda Ros, en la órbita del blasquismo, el principal impulsor en 1908 de la creación de un sindicato - «La Vedriola Alcudiense»-, en la esfera de la republicana y muy activa "Sociedad de Trabajadores del Campo". Uno y otro serían ejemplo de dinamismo y relativa coexistencia, agregándoseles en 1925, con elementos provenientes de ambos, "La Defensa del Campo", expresión de los grandes labradores de uno de los muy escasos lugares de su entidad demográfica con tres sindicatos... Producto, en última instancia, de un asociacionismo de largo aliento, idéntica e insólita circunstancia encontramos en otra pujante localidad valenciana: Alzira, centro desde la alborada del siglo de una triple potente corriente doctrinal, sosialista, blasquista y católica, cada una de ellas asentada sobre un movimiento sindicalista activo y creador hasta las vísperas mismas de $1936^{5}$.

4 A. S. Garrido Herrero se debe una notable monografía acerca del El sindicalisme católic a la Safor. Gandía, 1987, más valiosa y completa de lo que él, muy modestamente, afirma (pág. 19) y en la que sólo cabe lamentar el sesgo acusadamente unilateral que priva a algunas de sus páginas de matices que las enriquecerian por encima de toda ponderación.

5 Tan roborante sindicalismo ha tenido la fortuna de encontrar un insuperable estudioso en un joven contemporaneísta de la misma localidad, F. A. MARTínez Gallego, Agricultores solidarios. El cooperativismo en L'Alcúdia 1908-1999. L'Alcúdia, 2000, excelente monografía en la que, sin embargo, no deja de sorprender la persistente desatención hacia la temática religiosa en el origen y funcionamiento del centro confesional. Por su parte, un acusado apriorismo ante el cooperativismo confesional alcireño se observa, con la distorsión consiguiente de la realidad social que intenta describirse, en la notable tesis doctoral de P. Rovira Granero, Mobilització social, cambi polític i revolució. Associacionisme, Segona República i Guerra Civil. Alzira, 1900-1939. Valencia, 1996, bien que con indudable reluctancia, la documentada autora acaba por reconocer en diversos pasajes de su ágil estudio el peso trascendente del movimiento político y sindical católico en no pocos momentos del primer tercio del siglo $\mathrm{xx}$; tanto más resaltable cuando tan grande era tam- 
Como siempre, la intendencia acompañaba a los guerreros. En 1900 se creaba, a tono con el vanguardismo de las dimensiones más creadoras del catolicismo social valenciano, la "Caja de Ahorros y Monte de Piedad de Gandía», dispositivo esencial -con algunas interrupciones, secuelas de los antagonismos políticos entre las banderías de la comarca- hasta la guerra civil en la red asociativa confesional de toda La Safor, e incluso de las zonas aledañas ${ }^{6}$.

Sobre ella así como sobre la «Caja Rural de Torrente» recayó en parte la financiación de la obra cuya frustración en 1911 acibaró las últimas horas del P. Vicent, remecidas también por otros duelos y quebrantos. Un cuatrienio después de la muerte del gran pionero del catolicismo social hispano, la crisis en que la Gran Guerra hundiera a buena parte de la dinámica y vigorosa agricultura valenciana acabó por ganar a su idea federativa al conjunto de los labradores y terratenientes de militancia cristiana ${ }^{7}$. Con el aporte de once centros, en 1916 nacía la muy pronto potente e influyente "Federación Valenciana de Sindicatos Agrícolas" (FVSA), que, al iniciarse el siguiente año, contaba ya en el territorio valenciano y castellonense por el que se extendía su funcionamiento medio centenar de sindicatos, creciendo y creciendo hasta 1920 , sin descuidar en su avance las áreas femeninas. Ejemplo expresivo y ahorrador de mayores expensas exegéticas del frenesí sindical de los católicos valencianos tras el estancamiento de los primeros años diez es el de Vila-real de la Plana que en las postrimerías de 1919, fecha misma de su creación, sobrepasaba los

bién el ascendiente de las otras corrientes que le disputaban la influencia en la organización y gobierno de la dinámica comunidad alcireña.

6 El mencionado investigador castellonense S. GARRIDO HERRERO documenta algunos tramos en que la institución estuvo en manos de los adversarios políticos y sociales de los católicos gandienses, que, aunque a las veces, como se exponía en el texto, enfrentados en diferentes facciones partidistas, poseyeron ordinaria y habitualmente el control de la Caja. «l en aquest aspecte, cal reconoxéixer-ho, van realitzar els catòlics una intensa labor. Impulsant la Caixa d'Estalvis de Gandia, fundant sindicats agrícoles, cooperatives d'adobs i moltes iniciatives semblants van alliberar molts llauradors de la rapinya de l'usurer... al temps que van contribuir a mantenir-los sota el mantell de l'Església i allunyats de tota vel.leïtat revolucionària [...] Entre tots ells, que com véiem presentaven com a característica comuna l'estar d'una o d'altra manera relacionats amb la Caixa d'Estalvis de Gandia, van aconseguir que en poc de temps la Safor, contrastant amb l'anterior ensopiment, es convertira en la comarca valenciana amb un moviment catòlico-obrer més viu». El sindicalisme catòlic..., págs. 35 y 60 .

7 Cfr. V. SOLER, «La coyuntura agraria en el País Valenciano durante la Primera Guerra Mundial", Agricultura y Sociedad, 18 (1981), págs. 177 y ss.; artículo enjundioso en que, entre otras cosas, se destaca el permanente forcejeo de los sectores dirigentes de la economía valenciana con los estatales, preocupados ante todo por el abastecimiento interior, convirtiéndose «Madrid» en el origen de todos o casi todos los males de la comunidad. Como es conocido, la contienda tuvo una incidencia singular en el curso del regionalismo valenciano, tanto en su dimensión moderada como en la más radical. 
mil cien afiliados ${ }^{8}$. Muchos, una cantidad muy considerable de los cuales alcanzaron en su militancia cooperativista el sueño de su vida: ser dueños de unas hanegadas de tierra, conseguidas a través de las operaciones de compra-venta efectuadas por sus sindicatos; allí, como en otros múltiples puntos del País Valenciano y de toda España ${ }^{9}$.

Pero ni aquí, en tierras castellonenses, ni en las alicantinas vamos a acompañar detenidamente la historia del movimiento católico, no obstante disponer para las primeras de una excelente guía en los trabajos de un sobresaliente especialista, Samuel Garrido Herrero, suficientes para trazar un cuadro satisfactorio del asociacionismo confesional de las dos sedes que, en términos generales englobaban hasta 1960 la provincia castellonense (hasta 1960 la comarca del Alto Mijares pertenecería a la silla valenciana). El mismo autor ha hablado de la repetición cansina — déja vue-y hasta del hastío investigador provocado por la reiteración ad nauseam del esquema organizativo y, sobre todo, de los modos y prácticas del sindicalismo cristiano levantino. Sin ratificar por entero su afirmación ni aún menos seguirle en la desgana nacida de la foto fija ofrecida por dicha parcela del socialcatolicismo español -sin repetición no hay cuantificación y sin cantidades significativas no hay análisis convincentes-, pensamos, sí, que la reticulación del mapa valenciano por el movimiento que nos ocupa fue tan densa que el valor de las catas cobra en su estudio una entidad muy superior a la normal; lo que adquiere, obviamente, una característica aún más acentuada en una obra de síntesis ${ }^{10}$.

La panorámica, pues, del catolicismo social en las diócesis dertusense y segorbina habrá de ser más constreñida y apresurada de lo habitual en las descripciones de semejante naturaleza abocetadas en la presente obra. En una tierra en la que el influjo vicentiano se mostraría, lógicamente, de gran magnitud, no dejará de ser curioso que el «Círculo Católico de Artesanos» (1880), el único que con el de Jérica (1894) integraría el censo de las asociaciones de igual tipo erigidas en la diócesis segorbina, viese la luz en la capital de ésta conforme a las pautas y orientaciones que informaran los

8 Cfr. S. Garrido Herrero, Treballar en comú. El cooperativisme agrari a Espanya (19001936). Valencia, 1996, pág. 182.

9 ld., "El marco de aparición del Sindicato: una agricultura en transformación», en la obra colectiva Historia de la Cooperativa Católico Agraria y Caja Rural de Villareal (1919-1994). Villareal, 1994, págs. 65 y ss.

${ }_{10}$ Id., El sindicalisme catolic.... pág. 37. Bien que el autor se refiera de forma primordial al recurso de la más roma dialéctica marxista para explicar la actitud de los terratenientes y oligarcas ante el ccoperativismo confesional, sus palabras aluden igualmente a la uniformidad y repetición de la articulación y expresión del sindicalismo cristiano. 
cordobeses del dominico asturiano Ceferino González. La razón de ello se encuentra en que la verdadera puesta en marcha del "Círculo Católico de Artesanos" fue obra de su estrecho colaborador el barcelonés Francisco de Asís Aguilar y Serrat (1880-1899). Sin embargo, no obstante los prometedores comienzos del centro y el impecable pedigrí social e intelectual del citado prelado, sus esfuerzos por expandir la semilla social en la única diócesis que rigiera no se tradujeron en nada práctico, contribuyendo a hacer más desairada su figura el movimiento arrollador de la tortosina.

En efecto, los extensos territorios de la provincia castellonense incluidos en su geografía episcopal fueron inundados - sobre todo, en La Plana y el litoral- por una marea incontenible de círculos y asociaciones afines. Dos circunstancias fundamentales estaban en la raíz del hecho. En primer término y de modo muy singular, la actividad trepidante del $P$. Vicent, que se tomaría el empeño como cuestión personal; y, en segundo lugar, el influjo tampoco nada despreciable de uno de los focos de la espiritualidad y presencia social de los jesuitas en toda la España de la Restauración: el Colegio Máximo de Tortosa, en el que, al calor de Vicent, residente en él durante varios años, algunos de sus compañeros de orden mostrarian un inequívoco compromiso con la causa del socialcatolicismo ${ }^{11}$.

Al término de 1892, justamente cuando Vicent ponía colofón a la primera edición de la más conocida de sus obras, los círculos de Artana, La Vall d'Uixò, Sant Jordi, Vinaròs, Alcora, Onda, Castelló, Borriana, Vila-real y Nules, así como otros que habían quedado arrumbados en un camino con muchos altibajos, pregonaban a los cuatro vientos el fruto de una labor perseguida con tanto ardor como tenacidad. Las dificultades no habían sido escasas, y el halagüeño cuadro general no dejaba de ofrecer grietas y puntos negros. El nepotismo y el caciquismo eran quizá los más destacados desde las coordenadas del momento. La familia del "Tío Frare»,

\footnotetext{
11 «El Colegio de Tortosa [...] cumplía la doble función de casa de estudios y centro pastoral. Lo primero dominaba sobre lo segundo, pero la correlación de ambos elementos y la mayor o menor participación de los profesores y estudiantes en los ministerios o tareas de apostolado, determina lo que podíamos llamar la línea de comportamiento dominante. Los primeros años, el Teologado se caracterizó por un ambiente de movilidad y optimismo. Los devotos del Corazón de Jesús (Padres Gació, Martorell, Bombardó) y los profesores tocados por la afición social (P. Vicent) o por la revisión pedagógica ( $P$. Castellá) impusieron una movilidad pastoral y social que quedó interrumpida con el provincialato del P. Capell. El P. Vicent, que había logrado fundar diez círculos obreros en los alrededores, es alejado de Tortosa en 1883». M. REVUELTA GonzÁLEZ, La Compañía de Jesús en la España contemporánea. Expansión en tiempos recios (1884-1906). Madrid, 1991, 11, págs. 977-78. Vid en general, el muy completo estudio, no obstante la juvenil edad en que fuera redactado, del máximo especialista español en varias de las facetas del sindicalismo agrario novecentista, S. GARRIDO HERRERO, Los trabajadores de la derecha. La acción social católica en los Obispados de Tortosa y Segorbe. Castellón, 1986.
} 
especialmente la de su hermano, Joaquín Vicent, y su yerno, Salvador Guinot -notable local, diputado a Cortes, ninfa Egeria del movimiento católico castellonense-, no desaprovechó su posición privilegiada en la jerárquica sociedad castellonense para ramificar los tentáculos de su poder social y político en la propia capital de la provincia ${ }^{12}$. Su círculo, creado en 1881 , y, en especial, «El Gremio de Labradores de San Isidro» - 20 de marzo de 1896, convertido en "Sindicato Agrícola Obrero" once años más tarde-, por su irradiación sobre el cooperativismo de todo el seteptrión valenciano, fue palenque muy disputado entre carlistas, conservadores, liberales y cossieros, preservando la identidad liberal de una ciudad enfrentada ideológicamente con una provincia en parte tradicionalista. Ello se conseguiría después de mil acomodos entre cossieros - grupo de poder finisecular estrictamente capitalino- dueño permanentemente de la Diputación, pero no así del Ayuntamiento, feudo de los republicanos - aglutinados en torno a la figura del II duque de Tetuán, famoso por su camaleonismo-, y las fuerzas del bipartidismo stricto sensu; centrismo, de otra parte, no conseguido en la gran mayoría de los restantes círculos, en los que la corriente carlista sería preponderante ${ }^{13}$.

12 «La presencia del Padre Vicent en Castellón se registra múltiples veces con motivo de pronunciar alguna conferencia $u$ homilía, atendiendo los Círculos o también en la finca de la Devesa acompañado del prelado de la Diócesis para visitar a don Salvador Guinot y esposa. No pasa tampoco desapercibido al «Heraldo» el viaje rendido a Castellón -enero de l896 - por el Padre Vicent con motivo de visitar a «la noble Condesa de Pestagua, que siente por Castellón el mismo acendrado cariño que su esposo [...] y ha dado órdenes terminantes para que sean expropiadas a toda hora, los terrenos de su propiedad que han de aprovecharse para la construcción del camino paseo al Ermitorio de Lindón». A. GonzÁlez SoBACO, Los partidos políticos..., pág. 23. «Aquesta darrera entitat, una de les moltes cooperatives fundades al País Valencià i a Espanya per impuls del jesuïta Antoni Vicent, va prestar una especial atenció al cànem: va estudiar quins adobs quimics li eren més escaients, va establir una secció perquè els socis petits llauradors poguessen vendre en bones condicions la collita de fesols, va fer diversos experiments al seu camp de pràctiques... Gràcies a tot aixó, al començament del segle XX es va reforçar una polarització política que, com ha explicat M. Martí, arrancava com a mínim dels inicis de la Restauració. Castelló disposava d'una gran quantitatde jornalers i artesans, dos components essencials del món del cànem, que van ser captats de manera majoritària pel republicanisme, que ja s'havia convertit abans de la promulgació el 1890 del sufragi universal masculí en la indiscutible força hegemònica de la ciutat. Mentrestant, l'altre integrant bàsic de l'univers del cànem, els llauradors productors, es mantenien majoritàriament apegats a les tradicions catòliques $\mathrm{i}$ des dels primers anys del noucents, coordinats pel Gremí, van actuar com a bases d'una dreta confessional, quasi amb tanta capacitat mobilitzadora com la dels republicans, articulada de manera molt primerenca a la capital de la Plana». S. GarRido Herrero, «Explotació indirecta i progrés agrari: el conreu del cànem a Castelló (s. XVII-XX)», Recerques, 38 (1998), págs. 143-44. Vid. también un breve pero sumamente acucioso análisis del sindicato mencionado del mismo autor en Treballar en comú..., págs. 175-82.

13 Los «cossieros» - cossi: barreño, en el que se lavaban los trapos sucios...- representaron sucesivamente al partido canovista, al sagastino y nuevamente al conservador, sin tener que envidiar nada al «transformismo" de la península italiana, de tan grande influencia siempre en el Levante español. Vid. la destacada monografía, modelo en su género, de M. MARTí, Cossieros y anticossieros. 
Al contrario de la trayectoria normal en las restantes regiones del país, el periodo intersecular - prolongado casi hasta las vísperas de la Gran Guerra- contempló en una y otra sede del norte de la Comunidad Valenciana el crecimiento más que notable de unos círculos de obreros batidos en franca retirada, como decimos, en casi toda la nación, a compás y medida de la expansión de los sindicatos en la primera fase de su andadura. Ahora también el obispado de Segorbe figuraría en posiciones de retaguardia, añadiendo a la parva lista decimonónica tres nuevos centros - los de Navajas, Puebla de San Miguel y Chelva, incardinados, como se sabe, en la provincia valentina-; en tanto que, con cerca de veinte, el dertusense no dejará de incluirse en el pelotón de cabeza nacional.

Entre las estadísticas y la realidad es bien sabido que en muchas ocasiones existe gran distancia. En la porción castellonense de la diócesis tortosina, en 1921 tan sólo podrá constatarse la presencia de siete círculos. Su tiempo había definitivamente pasado, incluso en aquellas partes de España en que más terne fuera su empeño de fidelidad al modelo inicial.

En la misma provincia acabada de citar eran veinticinco los pueblos que en 1910 contaban ya con sindicatos agrícolas católicos en pleno funcionamiento, e incluso seis los establecidos en la sede segorbina. Conocida la zarandeada historia del sindicalismo confesional, tironeado tanto por el Estado como por los patronos - muchas veces o casi siempre identificados en sus miras obtaculizadoras-, nada sorprende que en todo el País Valenciano, en la fase económico-política concluida con el fin de la primera Guerra Mundial, la gráfica de dichas instituciones experimentase un espectacular descenso, mucho más acentuado que en la inmensa mayoría del Estado. Para mayor paradoja, tal estancamiento no significará siempre una bajada en la cuota de afiliación, produciéndose en numerosas ocasiones el fenómeno inverso, según comprobamos ya con el Sindicato Agrícola de Vila-real.

Con el golpe de Estado de Primo de Rivera puede darse por terminada, en más de un aspecto, el tercer y último ciclo fundacional y creador del sindicalismo confesional en el País Valenciano. A comienzos de 1923, su densidad social católica hacía que pudiera estimarse a Castellón como una de sus parcelas privilegiadas. En un suelo, como todo el levantino,

Burgesia i política local: Castelló de la Plana, 1875-1891. Castellón, 1985. Un año después y en la misma ciudad e institución veía la luz la destacada tesis de licenciatura de S. GARRIDO, Los trabajadores de la derecha, ya citada y esencial igualmente para este faceta del tema, en la que, por ejemplo, durante las elecciones municipales de 1909, sus adversarios católicos reconocerian que «los republicanos son mayoría absoluta en Castellón", pág. 176, etiam págs. 177-8 y 214-5. 
también muy fecundado por el sindicalismo neutro o laico, sus treinta y ocho sindicatos aglutinarán al 75 por ciento de los afiliados a los ochenta y un sindicatos de la provincia.

El Alto Palancia, el Baix Maestrat y la Plana Baixa se descubrirán como las zonas más propicias al desarrollo de la semilla sembrada por Vicent, expandida ya muy lejos de sus primitivos asentamientos litorales y capitalino. La hora de la plena adultez, y con ella la de la emancipación de la todopoderosa "Federación Valenciana», había sonado. Promediado junio de 1923, nacerá la «Federación Castellonense». Cuando en el fastigio de la primera dictadura las mostrencas e inerciales estadísticas eclesiales y estatales señalen la plenitud numérica del asociacionismo confesional, el castellonense, como todo el valenciano, dará muestras de una innegable vitalidad, en oposición a las corrientes desmovilizadoras iniciadas bajo la aparatosa superficie antedicha.

Incluso llegó a incorporarse ahora a la corriente el sindicalismo orcelitano de tan desmedrados inicios. En 1919 se constituiría, agrupando tan sólo trece centros, su «Federación de Sindicatos Agrícolas Católicos", arrebatada, sin embargo, en sus inicios por un frenesí creador, con la fulminante puesta en pie de numerosos sindicatos. Según se expondrá más adelante, la iniciativa episcopal jugó un papel decisivo en el cambio de panorama, en contraste con lo acaecido en el pontificado de un famoso obispo «intelectual». La escisión entre vida y pensamiento que el P. Mariana censurara en el buen rey Alfonso $X$-mientras contemplaba las estrellas olvidaba la tierra...- o, aún más exactamente, la definición más conocida de Benedicto XIV - parvus in solio, magnus in folio-, podía atribuirse con toda propiedad al obispo Juan Maura y Gelabert, tan alabado por Azorín debido a sus escritos y pastorales de temática social. No obstante la notabilidad de su obra bibliográfica, la diócesis alicantina permaneció casi al margen de la primavera sindical cristiana del trienio 1906-1909, no recuperando ya el tiempo perdido sino muy adelante, con la feliz continuidad de una triada episcopal de gran preocupación social y no menor compromiso práctico, conforme, insistimos, se volverá a poner de relieve ${ }^{14}$.

14 Cfr. el artículo de P. M. EGEA BRUNO, «Sindicalismo agrario en la sierra minera de Cartagena y en la diócesis de Orihuela. Dos modelos de comportamiento sindical en el Levante español. (1890-1920)", Anales de Historia Contemporánea, 1 (1982), págs. 200 y ss. Con mucho tino y justicia, uno de los pocos autores verdaderamente «clásicos» en la literatura histórica del sindicalismo español, J. Reventos CARneR, escribirá: «En 1908 en la Asamblea Social de Orihuela, el Obispo de la Diócesis Monseñor Maura Gelabert, uno de los precursores de la Democracia Cristiana en España, reforzará la acción cooperativa en su demarcación, con la fundación de varios Sindicatos Agrícolas, y en sus conferencias de orientación dirigidas a los obreros del Ateneo de Orihuela». El movimiento cooperativo en España. Barcelona, 1960, pág. 140. 
Con todo, la caracterización del prelado familiar del célebre político mallorquí de la Restauración necesita, para ser exacta, de algún matiz. La densa atmósfera religiosa, de acusados perfiles integristas, de la diócesis y la baja intensidad de la cuestión social dimanada de una estructura agraria con neto predominio del labrador medio, reforzaron la tendencia defensiva y autónoma de la región nacida con el conflicto dinástico. Su sensibilidad y energías sociales adoptaron así modalidades un tanto singulares, diferenciadas con frecuencia de las prevalentes en el asociacionismo confesional. Así a comienzos de siglo en Crevillente, Novelda y Petrel surgieron bancos y caja de ahorros confesionales destinadas in genere a promover el ahorro y el crédito sin destino específico o preferente hacia las clases obreras. La más conocida de todas estas instituciones, la «Caja de Ahorros y Monte de Piedad de Nra. Sra. de Monserrate" - fundada en Orihuela en 1904 aunque legalizada dos años más tarde-, encarnaría en su plenitud esta diversidad del socialcatolicismo alicantino. Tras el círculo de obreros erigido en la capital de la provincia en 1907, el sindicalismo plantará sus cuarteles en Caudete -1909- y Muchamiel -1911-, rebrotando, empero, la corriente particularista con la creación en 1913 en la capital del obispado del "Círculo Instructivo Obrero", bien expresivo en su titulación de los fines que primordialmente perseguía.

Pero no todo era desfase ni arcaismo en la acción social cristiana de la diócesis regida entonces por el obispo Maura. Su anterior semblanza «social» requiere más de una y sustantiva matización para aproximarse a la realidad. Esta fue que, en verdad, logró conciliar en diversos momentos y actividades la reflexión teórica con el interés por sus aplicaciones. Una de las demostraciones más palpables de ello se encuentra en su decidida iniciativa por romper con el modelo vicentiano y acercarse al preconizado en Cataluña por el P. Palau, cuya obra seguía de cerca y estimaba. Igualmente su respaldo sería total al "Consejo Diocesano de las Corporaciones Obreras Católicas de la Diócesis de Orihuela», de la que aceptaría la presidencia de honor alentándola sin desmayo al igual que hiciera con los «Consejos Arciprestales», centrados en esencia en crear el clima y las estructuras adecuadas para la difusión de cooperativas y cajas rurales por toda la sede ${ }^{15}$.

La capital del antiguo reino de Valencia fue, con Zaragoza y Valladolid, uno de los tres ejes que articularon el catolicismo social español. Con mayor fuerza y éxito que las otras dos logró combinar teoría y praxis, pre-

15 Un libro muy característico del moderno hispanismo anglosajón ofrece la claridad en la síntesis del buen trabajo de las actuales hornadas historiográficas dedicadas a la investigación del pasado más próximo de nuestra agricultura. Vid. J. Simpson, La agricultura española (1765-1965): la larga siesta. Madrid, 1997, págs. 186-196. 
sentando así la imagen más completa y armónica del socialcatolicismo hispano. Uno de sus vectores menos ponderados, el educativo, aquistaría en tierras levantinas sus cotas más altas al alcanzar en ellas los máximos réditos su instrumento clave en la promoción cultural de los sectores obreros: los «Patronatos de la Juventud». Por más devaluados que estén algunos de sus sumandos - mera concesión, hoy por hoy, en el estado de la investigación, a los furores críticos de algunos de sus estudiosos-, el balance conclusivo de sus tareas pedagógicas desarma las prevenciones más arraigadas acerca del verdadero resultado de una labor esencial en el campo de la actividad social cristiana. Es cierto que la irradiación de una de las universidades más prestigiosas por entonces de la nación no dejó de ser un poderoso factor coadyuvante para esta cosecha; pero ello en manera alguna cabe esgrimirlo como objeción, ya que sería fácilmente rebatible al manifestar la porosidad del catolicismo social valenciano, algunos de cuyos miembros más relevantes tuvieron estrechos lazos con el Alma Mater de la región, a la manera de Rafael Rodríguez de Cepeda, José Gestoso o Juan Reig Genovés.

Las gotas esparcidas al desgaire en estos apuntes acerca de la presencia femenina en el sindicalismo confesional quizá hayan servido para colocar en su adecuado puesto la rama cultivada en Levante, situada, como la masculina, muy en cabeza del nacional. El tradicional y consabido «Sindicato de la Aguja» evidenció desde el primer momento una pujanza casi desbordante, con canales que irradiaban por todo el ancho mundo de la costura, entonces, quizá, más dilatado y con mayor capacidad de empleo y mano de obra que en la actualidad. Esta vitalidad no sólamente se expresó en una casi asombrosa expansión numérica de gremios y afiliados, sino, producto de ello, en un espíritu cooperativo adulto y combativo, lo que prestaría al sindicalismo femenino valenciano un notable eco en la vida de la región e incluso en la de todo el país, según quedaría registrado, entre otros hechos de alcance similar, en su descollante actividad a la hora de articular el asociacionismo de género en la unidad de todo el profesional, conforme se verá más adelante. Antes y después de ésta, el cooperativismo valenciano femenino acaso fuese el más creativo y renovador entre todos los españoles, de fisonomía, en conjunto, tan atractiva como robusta. La sóla evocación de la «Confederación Regional de Sindicatos Católicos obreros-Femeninos Nuestra Señora de los Desamparados" y la trepidante y reivindicativa labor que desplegara por todo el territorio levantino bastarán para testimoniarlo ${ }^{16}$.

16 La documentada tesis doctoral de R. M. CAPEL, El trabajo y la educación de la mujer en España (1900-1930). Madrid, 1982, hace justicia al papel y esfuerzo del sindicalismo femenino valenciano. Vid. en especial, págs. 243-4, 47 y 262 y ss. 
La misma capacidad modernizadora acabada de constatar en varios ámbitos del cooperativismo valenciano, se pone de relieve en la parcela quizá más debatida del sindicalismo confesional hispano. En efecto; pocos de sus ejemplos ofrecerán una mejor ilustración jurídica y laboral de lo afirmado. Sus medios -locales, créditos - e instrumentos - asesoría, documentación bibliográfica - facilitaron y potenciaron la capacidad de iniciativa de uno de los campesinados más dinámicos y laboriosos de toda la nación. Merced a la conjunción feliz - pero no, naturalmente, idílica o arcádica- de tales elementos la crisis agrícola intersecular - agravada en el País Valenciano por los últimos coletazos de filoxera- pudo superarse de modo impensadamente halagüeño. Los cambios estructurales a que dicha gran crisis dio lugar en la propiedad de la tierra y en los cultivos -el nitrato de Chile convertido en maná del naranjero_, hallaron -importará repetir - una de sus máximas plasmaciones en el campo y la horta de la región ${ }^{17}$. La expansión de los cítricos y productos hortifrutícolas tuvieron en los llauradors suficients de círculos y sindicatos a uno de sus principales artífices. El desarrollo del capitalismo agrario que el hecho entrañó está hoy ya fuera de dudas, que permanecen, sin embargo, a la hora de analizar el papel de sus diferentes actores ${ }^{18}$.

17 «Els potents sindicats valencians [...] estaven integrats per una barreja de jornalers (en ocasions, més del $40 \%$ dels afiliats), petits explotadors i propietaris d'una certa envergadura, però el nucli motor de tots ells era una capa de mitjans agricultors suficients amb una innegable capacitat emprenedora, cosa que els oferia perspectives d'acumulació en les conjuntures favorables i els va permetre actuar com un dels motors del desenvolupament agrari valencià". S. GARRIDO HERRERO, El cooperativisme segons l'Església..., pág. 71. El mismo autor completará la descripción y la tesis: «Per contra, en aquelles comarques i localitats on el sindicalisme agrícola va descansar sobre un nucli significatiu, en ascens però prèviament consolidat, de xicotets i mitjans llauradors amb una certa capacitat d'acumulació en les conjuntures favorables, si que va servir per a donar una major solidesa a aquestes capes que, partint d'una base camperola, estaven promocionant un nou capitalisme agrari. I també va servir, però subsidiàriament, per a facilitar l'accés dels desposseïts a la propietat; i per a evitar que els propietaris més dèbils la perdessen. Però aquesta mena d'entitats només van ser abundants a partir de la Primera Guerra Mundial. En part, perquè l'ambient de crispació social característic del «trienni bolxevic» va facilitar que, com a resposta defensiva, l'administració i els majors terratinents, abandonant les anteriors reticències, impulsen el cooperativisme. Però, sobretot, perquè va ser precisament aleshores quan els «agricultors suficients", afectats per les dificultats econòmiques que provoca el conflicte europeu, es van llançar de manera decidida a participar-hi». Id., Treballar en comú..., págs. 279-80.

18 «...l'agrarisme valencià no cessará d'emetre protestes en contra de la política comercial espanyola. En realitat, però, no protestava perqué aquesta lesionés els seus interessos, sinó per evitar que pogués lesionar-los en el futur. Quan apareix alguna dificultat concreta, les queixes adquireixen tonalitats catastrofistes, però simultàniament no cessa d'indicar-se que els propietaris, en vista que els mercats europeus absorbien tot el que se'ls enviava, sacrificaven la qualitat a costa de la quantitat $i$ havien convertit els horts en «fàbriques de taronges».

Mentrestant, les pressions i les negociacions en el «mercat polític» sí que aconseguien que alguns dels conreus del País Valencià gaudissen d'una elevada protecció aranzelària. Com que un gran nombre de propietaris -i entre ells molts dels més significats agraristes- es dedicaven a 
Las contradicciones en que dicho avance se debatiera y la dialéctica de poder que implicase en el interior de las organizaciones confesionales, continúan en plena discusión por parte de los historiadores de la agricultura, tan inexplicable como dolosamente desdeñosos frente al sindicalismo agrario católico, muy superior en términos cuantitativos a cualquier otro del mismo carácter. Viejas teorías descubren hodierno una patética inanidad, mas sin perder vigencia académica, en tanto que otros métodos de análisis más adecuados se hacen demasiado esperar por la pereza inercial del oficio de historiador en España.

Al margen del futuro rumbo de la historiografía contemporaneísta, el acceso a la gran propiedad -en términos levantinos - de algunos agricultores pequeños y modestos y, en todo caso, su papel de agentes de indudable importancia en las hondas transformaciones del campo valenciano del primer tercio de la centuria pasada, revelan que el antagonismo clasista en el seno de las organizaciones cristianas de la región -así como en las de toda España, testigo del mismo cambio- no tuvo que ser paralizador ni esterilizante. Intereses comunes y objetivos afines debieron quizá prestar una solidaridad mayor de la supuesta hasta el momento a los diferentes estratos; $y$, desde luego, es asaz probable que la fuerza torcedora y manipuladora de los capitalistas más caracterizados no poseyera el vigor comúnmente atribuido. Por otro lado, la «peculiar» postura de los grandes propietarios valencianos frente al proteccionismo de industriales catalanes y propietarios trigueros castellano-andaluces, favorecidos por los aranceles de 1891, 1906 y 1922, acortaría aún más las distancias entre todos los labradores levantinos, contestatarios - nunca destemplados...de la política estatal opuesta a la exportación de sus cítricos ${ }^{19}$; pero al mismo tiempo aventajados usufructuadores de un proteccionismo muy beneficioso para el cultivo alternativo de cereales tan practicado sobre todo

produir articles d'exportació juntament amb d'altres destinats a satisfer la demanda interior, la incoherència que representava el fet que aquesta mena de reivindicacions provinguessen de persones $i$ institucions que pretenien ser els portaveus de l'agricultura exportadora -i que eren reconeguts com a tals - deixa de ser-ho. Això - sempre al costat de l'ininterromput auge exportador - ajuda a explicar per què els catolicoagraris valencians es van mantenir fidels a la CNCA. I, més en general, hauria de ser un element que caldria tenir en compte a l'hora de tractar d'entendre per què la classe dirigent valenciana va continuar mantenint tan bones relacions amb el poder central després de 1891 i de 1906». ID, «Realment eren lliurecanvistes? Les peticions aranzelàries de l'agrarisme valencià al començament del segle XX». Afers, 36 (2000), pág. 393.

19 El tema es complejo. Como expone J. M. Serrano Sanz en un excelente artículo, aunque la política estatal, por su acentuado proteccionismo, se manifestaba «opuesta a la exportación" de los cítricos, pretendía simultáneamente, en búsqueda de equilibrar la balanza de pagos, propiciar la de los productos agrícolas —no así los ganaderos: protesta eterna de Galicia- mediante la firma de tratados de Comercio, «Sector exterior y desarrollo en la economía española contemporánea», Papeles de Economía Española, 73 (1997), págs. 308-335. 
por los grandes propietarios, bien que en el regadío solieran hacerlo por vía indirecta: recurriendo a arrendatarios ${ }^{20}$.

La mayor parte de la bibliografía especializada ha formulado análisis ingeniosos con el indisimulable fin de salvar o al menos atenuar dichas contradicciones que, en último término, invalidarían el planteamiento general y las tesis más divulgadas acerca del sindicalismo rural católico. La doble actitud, el ambivalente papel representado por los propietarios impulsores y controladores de los sindicatos al compatibilizar su acción fomentadora - tan incentivada y pandereteada por la Iglesia - con la restrictiva y aun demoledora de las estructuras organizativas de tales centros así como el decidido aprovechamiento de las importantes ventajas concedidas a su funcionamiento por el Estado, hicieron posible la mínima pero suficiente conciliación de los intereses de clase de la gran burguesía agraria con la promoción del modesto campesinado. En la agricultura con mayor fuerza y capacidad modernizadoras del país, el avance regular y sostenido de su sector punta - la citricultura, creciente e imparablemente extendida desde finales del XIX- desdibujó o azemó - sobre todo, en los momentos de auge, que fueron muy largos en el primer tercio del Novecientos- las aristas conflictivas en las relaciones de clase; permitiendo si no el colaboracionismo, sí la apertura de de los grandes propietarios el ascenso de los pequeños y, en especial, de los medianos, usufructuadores también por su duro trabajo de las buenas coyunturas y expansivos ciclos ${ }^{21}$. Perspicaces estudiosos de la agricultura levantina han denominado, a estos últimos agricultores «suficients», dueños de un mínimo capital de explotación que los hacía muy aptos para el arrendamiento de las posesiones de unos grandes propietarios que, bajada la barrera de los recelos políticos y sociales de los primeros momentos, se desvivirían, pasada la crisis intersecular, por arrendar sus tierras a unos sectores sin problema alguno de financiación propia y de plena garantía ${ }^{22}$.

20 «... a mesura que la investigació ha avançat en la línia apuntada l'any 1985 per R. GaraABou en Un fals dilema, sembla més difícil continuar parlant de la coexistència d'una agricultura valenciana dinàmica i orientada cap a la exportació amb una altra estancada i retardatària protegida pels aranzels. Aquesta darrera no va quedar al marge del procés de canvi i de millora. Però és que, a més, sovint por detectar-se una jorta imbricació entre totes dues, fins al punt que resulta escassament operatiu establir una distinció categòrica entre «sectors exportadors" $i$ "sectors protegits", ja que era molt habitual que un mateix productor, gran o menut, participés alhora en els primers $\mathrm{i}$ en els segons, servint-se de finques distintes o dels conreus que se succeïen al llarg del cicle agrícola en una única parcel-la». S. GaRRido, Realment eren lliurecanvistes?..., pág. 395

21 S. CALATAYUd y J. MiLLÁN, «Un capitalisme agrari amb «rendistes» i «camperols»: una aproximació a la dinàmica de la societat local al regadiu valencià durant el segle XIX», Estudis d'Història Agrària, 10 (1994), págs. 27-56.

22 "A partir dels primers anys del segle xx la Plana es va configurar com una de les àrees amb un moviment cooperatiu més potent de tot Espanya. A més de vendre adobs, els sindicats 
Interpretación alambicada y aguda, que no sirve, empero, para explicar por entero la escasa o nula subordinación que los pequeños y medianos campesinos mostraron en los núcleos del cooperativismo católico respecto a terratenientes y latifundistas. A rebours de encanecidos prejuicios, un hecho se impone con patencia en la investigación actual de la historia de la agricultura europea y española: el papel propio y no ancilar del pequeño labrador, elemento fundamental si no clave de la modernización que las explotaciones agroganaderas experimentasen a raíz de la profunda crisis finisecular decimonónica ${ }^{23}$. Existentes en muchas comarcas con anterioridad al boom cooperativista de las primeras décadas del novecientos, utilizaron a fondo los medios y servicios de las organizaciones católicas a las que aportaron iniciativa y fuerza, hasta convertirse en pieza esencial del desarrollo rural del primer tercio del siglo pasado. Visible y constatable el hecho en varios lugares del país, en la comunidad valenciana se recortaría como elemento básico del dinamismo y progreso de su agricultura.

Tal vez - y nos deslizamos en el pantanoso terreno de lo futurible...ello hubiera sido posible en otro marco y circunstancia, pero la historia

agrícoles -que, encara que no exclusivament, eren principalment sindicats catolicoagraris-van desenvolupar una important activitat crediticia (caixes rurals), venien insecticides i disposaven d'equips per a fumigar els horts de tarongers, feien arribar als socis els consells de tècnics agricoles... La situació més fregùent al camp espanyol del primer terç del segle xx va a ser que les cooperatives, que estaven integrades principalment per pagesos pobres i que no rebien un suport decidit per part de l'Estat, haguessen de fer front a una permanent falta de recursos que comprometia l'èxit de la seua actuació. No va ser així a la Plana gràcies a existir-hi un sector important de llauradors acomodats que, en part per motius socials i polítics, actuaven com a motors d'aquell moviment i li donava solidesa, cosa que va servir perquè els camperols més humilds compressen adobs i accedissen al crèdit en condicions més favorables que als llocs on el cooperativisme es va desenvolupar menys. I va servir, també, perquè els sindicats católicoagraris fossen capaços d'atraure un nombre bastant considerable dels jornalers que aspiraven a convertir-se en petits propietaris». S. GARRIDO, «El conreu del taronger a la Plana de Castelló: agricultura comercial, propietat pagesa i treball assalariat (1850-1930)», Estudis d'Història Agrària, 13 (2000), págs. 223-24. Referiéndose a la década de los veinte pero con plena vigencia en los decenios inmediatamente anteriores, escribe E. M. OBIOL MENERO: «El arrendamiento constituía un régimen de tenencia observable en las grandes masias del interior, pero en modo alguno generalizable al territorio de Castelló, ya que en función del acentuado minifundismo, tanto en el secano como en el regadío, la propiedad directa y la aparcería eran ampliamente predominantes», «El registro de la propiedad expropiable en la provincia de Castellón. La situación agraria en el primer tercio del siglo XX", Agricultura y Sociedad, 48 (1988), pág. 249.

23 «Los sindicatos católico-agrarios valencianos enviaron durante aquellos años a los mercados extranjeros naranjas, cebollas y otras producciones de huerta, pero también arroz: por medio de $R$. O. (18-III-1920), se concedió en exclusiva a la Federación valenciana un permiso para exportar el arroz de la provincia de Valencia. Lo que puede dar una pista más sobre por qué algunos sectores de propietarios acomodados estaban potenciando ahora el cooperativismo sirviéndose de las facilidades concedidas por motivos sociales a los sindicatos, habrían conseguido participar de los beneficios derivados de los altos precios de los alimentos de primera necesidad en el mercado europeo y esquivar legalmente las trabas a la exportación». S. GARRIDo HERRERO, «El cooperativismo agrario español del primer tercio del siglo xx", Revista de Historia Económica, 1 (1995), pág. 129. 
verdadera, la construida empíricamente, muestra que sólo -o al menos mayoritariamente- acaeció en el seno de un sindicalismo confesional con mil goteras y vacíos, pero que aún así encuadró y encauzó a unas gentes caracterizadas por su individualismo, en particular, en Valencia...; bien que tan consolidado estereotipo pudiera encerrar, en el Pais Valenciá, y fuera de él alguna -o mucha- sustancia tópica, detectada con creciente fuerza por la más reciente historiografía. Todo lo que a menudo era potencial o latente se convirtió en acto dentro de los sindicatos, cuyos miembros explotaron a fondo la extensa gama de sus servicios, comenzando, claro, por los económicos y financieros. Si en algunos territorios del país no fue así, como quiere una tesis totorresista y documentalmente voluntarista, tal no sería, desde luego -insistiremos sin temor al cansancio-, el caso de Valencia, haciendo con ello todavía menor la dependencia del modesto y pequeño campesinado del grande. En las zonas de mayor intensidad en la teoría y praxis del cooperativismo cristiano su vanguardia, los estratos del campesinado medio de innato o congenial espíritu empresarial -los suficients en el País Valenciano, los en Cataluña, los dinámicos bodegueros riojanos, los de la Vieja Castilla o Navarra, entre otros - tuvieron, en últimos término, bien en cuenta, que, no obstante la tentacular malla caciquil, era posible servirse del Estado - pese sus indefiniciones tácticas, fuente y cobertura de los bienes e instrumentados por cooperativas y sindicatos- para lograr sus aspiraciones de progreso y bienestar.

Lá alusión caciquil conduce a constatar que el saldo político del asociacionismo cristiano levantino es manifiestamente una de sus facetas más suscitadoras hoy de interés. La lenta pero imparable movilización ciudadana operante en la segunda fase de la Restauración encontró en el campesinado católico una aportación quizá cuantitativamente comparable al del obrererismo y mesocracia urbanos blasquistas. Aunque con mucha menor intensidad y espectacularidad del desenganche del canovismo puro y duro de las clases medias bajas o el proletariado de algunas zonas de la nación y de la misma comunidad valenciana, la adultez cívica, y con ella la entrada en una cultura política incipientemente democrática, se disfrutaría por gran parte de los integrantes de las organizaciones socialcatólicas levantinas. Su status material permitiría a los agricultores suficients una toma de posiciones propias, al margen de los intereses banderizos o caciquiles de una burguesía agraria consciente - bien que tal vez a su pesar- de que la autonomía económica entrañaba la política ${ }^{24}$.

\footnotetext{
24 Vid el capítulo V de S. GARRIDO, Treballar en comú...
} 
Obvias constricciones de espacio impiden, no obstante, una aproximación siquiera epidérmica al tema. Las razones de brevedad no impedirán que, tiempo adelante, procuremos inventariar algunas de las consecuencias de mayor entidad derivadas de la existencia, en la Valencia de los decenios iniciales de la centuria novecentista, de un campesinado confesional económica y socialmente promocionado.

El que, por el contrario, sí resultará por completo excluido de las presentes páginas, será otro de igual relevancia, como es, en un movimiento y actividad presididos, invariable y mayoritariamente, por una estricta confesionalidad, el religioso. Ni por gusto ni por deseo aunque, sí, algo más por oficio, nos sentimos inclinados a penetrar en el ámbito de las conciencias. Sin embargo, el estudio, por ejemplo, de los niveles de práctica sacramental en las organizaciones asociativas confesionales o el análisis de sus bibliotecas, conferencias y representaciones de índole religiosa contribuirían, indudablemente, a una mayor riqueza interpretativa del tema en su conjunto. Mas si éste, a pesar de los notables trabajos de que ha sido objeto, aún permanece enseñoreado por las brumas y celajes de las formulaciones desiderativas y voluntaristas debido a la ausencia de fuentes y repertorios documentales sólidos y abundantes, puede imaginarse fácilmente cuál será el panorama dominante en la faceta aludida. Lástima grande sin duda que la porción de nuestro país en la que más elevado nivel alcanza una de las áreas mejor cultivadas de la historiografía contemporaneísta española - la agraria -, muestre mayor intonsidad la más raquíticamente roturada, la eclesiástica. 